UNIVERSITY OF GOTHENBURG

SCHOOL OF BUSINESS, ECONOMICS AND LAW

WORKING PAPERS IN ECONOMICS

No 385

\title{
Social Background, Cooperative Behavior, and Norm Enforcement
}

Martin Kocher, Peter Martinsson and Martine Visser

October 2009

ISSN 1403-2473 (print)

ISSN 1403-2465 (online) 


\title{
Social Background, Cooperative Behavior, and Norm Enforcement ${ }^{+}$
}

\author{
Martin Kocher, Peter Martinsson, and Martine Visser*
}

\begin{abstract}
Studies have shown that there are differences in cooperative behavior across countries. Furthermore, differences in the use and the reaction on the introduction of a norm enforcement mechansism have been documented in cross-cultural studies, recently. We present data which prove that stark differences in both dimensions can exist even within the same town. For this end, a unique data set was created, based on public goods experiments conducted in South Africa. Most of the group differences can, however, be explained by variables accounting for social capital and social environment, such as trust or household violence.
\end{abstract}

Key Words: Cooperation, public goods, punishment, experiment, social capital, South Africa

JEL Classification: C72, C91, H41, Z13

\footnotetext{
* Martin Kocher, Department of Economics, University of Munich, Geschwister-Scholl-Platz 1, D-80539 Munich, Germany, (email) martin.kocher@lrz.uni-muenchen.de; Peter Martinsson, Department of Economics, University of Gothenburg, Box 640, 40530 Gothenburg, Sweden, (email) peter.martinsson@economics.gu.se; Martine Visser (corresponding author), School of Economics, University of Cape Town, Private Bag, Rondebosch, 7700 Cape Town, South Africa, (email) martine.visser@uct.ac.za.

+ We would like to thank Simon Gächter, Olof Johansson Stenman, Eva van den Broek and participants at the ESA meetings in Nottingham, UK, and Tucson, AZ, USA, in 2006, at the Nordic Workshop on Behavioral and Experimental Economics in 2006, and at seminars in Amsterdam, Frankfurt, Jena, and the Dead Sea for their helpful comments, as well as Benedikt Herrmann for very helpful suggestions regarding the research design. We are also indebted to the Western Cape Department of Education in South Africa for facilitating this research. Financial support from the Swedish Agency for International Development and Cooperation (Sida) to the Environmental Economics Unit at the University of Gothenburg, from Vetenskapsrådet (Swedish Research Council), and from Jubileumsfonden at University of Gothenburg is gratefully acknowledged. Martin Kocher also acknowledges financial support from the ENABLE Project under the European Union's 6th Framework Program. This paper reflects the views of the authors, and the European Union is not liable for any use that may be made of the information contained herein.
} 


\section{Introduction}

Cooperative behavior is an important component in the daily lives of humans and animals. In the case of humans, it shows up in a range of activities, from sharing food and investing effort in teamwork to keeping the environment clean, using common resources diligently, joining in collective action, and actively participating in elections. In economics, the nature of cooperation and its patterns are usually studied in the context of social dilemmas or, equivalently, in the private (voluntary) provision of a public good. ${ }^{1}$ It is a welldocumented fact from numerous experimental studies both in the laboratory and in the field that people contribute more to public goods, on average, than predicted by the selfish and rational model of the homo oeconomicus, even in one-shot interactions (for overviews, see, e.g., Ledyard 1995; Zelmer 2003). There is also solid evidence that costly norm enforcement devices, such as decentralized sanctions that would not be used by money-maximizing agents, are very effective in raising contribution levels to a public good (e.g., Fehr and Gächter 2000; Andreoni et al. 2003; Masclet et al. 2003; Anderson and Putterman 2006; Gürerk et al. 2006; Carpenter 2007; Sefton et al. 2007). ${ }^{2}$

Recently, several studies have documented differences in cooperative behavior across countries. Cultural learning or the stronger cohesion of social norms within a culture makes such differences across countries likely. While the evidence is not, yet, conclusive especially with regard to the mechanisms that shape cooperative norms or cooperative behavior in a society, cooperative behavior has been found to be related to some measurable "cultural" variables that are intuitively appealing (see, for instance, Herrmann et al. 2008, and Gächter and Herrmann 2009). However, more evidence is clearly necessary in order to be able to draw final conclusions on cultural influences on cooperative and norm enforcement behavior.

This paper contributes to the literature on cultural determinants of cooperation and norm enforcement. It proceeds along a different line than cross-cultural studies by focusing on differences within a country across cultural groups. As far as we are aware, we are the first to show that there can be stark differences in both cooperative behavior and norm enforcement behavior within the same country within a very small radius of geographical distance. However, most of the group differences can be explained by variables accounting

\footnotetext{
${ }^{1}$ Equivalently, it has also been studied in the context of the use of a common pool resource.

2 In political science or social psychology, related studies were conducted even earlier by Yamagishi (1986) and Ostrom et al. (1992), for example.
} 
for social capital and social environment or social background, such as trust or household violence.

More specifically, we combined a standard linear public goods experiment, conducted in four different communities in Cape Town, South Africa, with self-reported questionnaire data on individual characteristics and social background variables, which focused on school, home, and neighborhood conditions. Participants in the experiments were high school students with less than two years to graduation, attending four selected high schools: (1) a school from one of Cape Town's white high-income neighborhoods; (2) a school located within a colored middle-income neighborhood; (3) a school representing the low-income African communities located in older neighborhoods where most of the housing development is permanent; and (4) a school located in a low-income African community where housing development is classified as informal. For purposes of elucidation, the schools are labeled (1) white, (2) colored, (3) African permanent, and (4) African informal, respectively. ${ }^{3}$ Due to the legacy of apartheid, high-income and middle-income people, on one hand, and low-income people, on the other, are still mostly divided along ethnic and racial lines; thus, our groups were very homogenous. ${ }^{4}$ In the terminology of Harrison and List (2004) we are conducting an artificial field experiment.

Three features of our design gives us a higher level of experimental control over behavior than in many related studies: first, in contrast to several other experiments, and in contrast to experiments that are embedded into representative surveys, we kept the social distance of individuals constant. Subjects in our experiment knew that they would interact with members of their own groups. Second, choosing high school students as participants has the advantage that their social background, such as their integration into their communities or into school organizations, is not difficult to control for. In addition, because our subjects have not yet entered the labor market, their inter-connections with other communities are limited. Third, although we still had a salient cultural variable through the choice of schools, we avoid all the problems associated with experiments that are conducted in different countries. In fact,

\footnotetext{
3 In the demographic context of South Africa the groups we refer to as white, colored and African are comprised of people from European, mixed and indigenous ancestaries, respectively.

4 Due to a combination of the abolishment of discriminatory legislature and employment policies, affirmative action requirements within the government and the private sector, and African empowerment initiatives a percentage of both middle- and high-income groups from both the colored and African population has, however, emerged recently in South Africa.
} 
our four high schools were located in four different communities less than 15 kilometers apart from each other. ${ }^{5}$

By controlling for the social background of decision makers, we were able to go beyond most existing studies that take only a very limited number of individual determinants of behavior (such as gender, age, and similar variables) into account. Specifically, besides using individual socio-demographic information, we assessed the influence of social background on cooperative and norm enforcement behavior by controlling for 1) attitudinal measures of trust (trust); 2) behavioral measures of an individual's level of integration into one's peer group and community (social integration); and 3) behavioral measures on norm violation, such as the level of crime incidents in one's neighborhood (community crime), and norm enforcement in one's home and community (household violence).

Our main empirical results reveal the existence of differences in cooperative and norm enforcement behavior across the four groups. Furthermore, we are able to show that some variables accounting for social capital and social background, such as trust and household violence, are consistently related to human cooperative and norm enforcement behavior. Therefore, one important lesson from our study is that leaving such variables out of the analysis could have led us to premature conclusions about the level of cooperativeness and about norm enforcement of our four different communities. In other words, we would have ascribed differences to "cultural" differences across communities without knowing that at least part of the effect could also be driven by different backgrounds of the decision makers.

The remainder of this paper is organized as follows. In section 2, we give a short overview of the related literature. Sections 3 and 4 present our experiment design and its details. Section 5 gives some more information on our subject pool, followed by the results in section 6. Finally, section 7 concludes the paper.

\section{A Brief Overview of Related Literature}

The economics literature on cooperation and norm enforcement is huge, and the following brief overview is far from being complete. As already mentioned in the previous

\footnotetext{
5 Ockenfels and Weimann (1999), who studied differences in cooperative behavior among individuals in former West and East Germany, also mention the advantage in terms of control in their experiment, compared to a multi-national setting. They document significant differences in cooperative behavior between the two groups, with subjects from West Germany being more cooperative.
} 
section, the influence of culture on cooperation is usually studied by comparing experiments conducted in several countries. A number of papers, such as Brandts et al. (2004) or Burlando and Hey (1997), have compared student samples across countries. While Brandts et al. (2004) did not report any cultural differences of behavior in Japan, the Netherlands, Spain, and the United States, Burlando and Hey (1997) found significantly more free-riding behavior among British students than among Italian students. In a more complicated game than the voluntary contribution mechanism, Cason et al. (2002) provided evidence for a behavioral difference in cooperation between American and Japanese students. In Kocher et al. (2008), the extent of unconditional cooperative behavior was the same in Austria, Japan, and the United States, but the Americans had a stronger degree of conditional cooperation. Using unusual subject pools, Henrich et al. (2005) found a difference between cooperative behavior among small-scale societies around the world, and Carpenter et al. (2004) reported extremely high levels of cooperation among individuals living in urban slums in Thailand and Vietnam.

While the bulk of studies focuses on cultural differences in cooperative behavior and their possible determinants, norm enforcement behavior in social dilemmas have hardly been analyzed in the economics literature. Two notable exceptions are Gächter and Herrmann (2007, 2009). They conducted public goods experiments in Russia and found differences between rural and non-rural participants and that the efficiency-enhancing potential of punishment may be culture-specific. More specifically, they reason that there might be cultural factors that drive the fraction of spiteful or anti-social punishers (defined as players that punish other players who contribute at least as much as them). A high proportion of spiteful punishers can counterbalance the positive effects of punishment due to the high efficiency costs associated with it. Another exception is Herrmann et al. (2008), who provided evidence on punishment behavior in social dilemmas in 16 places around the world. Interestingly, they found that anti-social punishment was widespread and negatively correlated with norms of civic cooperation and the strength of the rule of law in a country. Finally, Carpenter et al. (2004) provided results on punishment (termed “social disapproval” in their paper) and its determinants.

Studies that mainly assess the impact of other-than-cultural determinants of cooperative behavior are also numerous. The evidence from the literature regarding gender is mixed, with several studies on both sides plus others that show no significant effect in either direction (for details, see Croson and Gneezy 2009.) Age is rarely controlled for in cooperation experiments because the variance in age for the standard subject pool of students is quite small. Harbaugh and Krause (2000) reported differences between child behavior and adult behavior, but on average the inclination to cooperate has, so far, not been shown to be different across different adult age groups. 
Another set of determinants for cooperative behavior is associated with the social background of an experimental subject, such as an individual's integration into one's community and an individual's level of trust towards a generalized "other," sometimes also referred to as social capital. Anderson et al. (2004) provided mixed evidence regarding the correlation between cooperation and trust. Gächter et al. (2004) found, in a one-shot public goods experiment in Russia, that the socio-economic background affects trust attitudes, but that there is no separate influence of socio-economic variables on cooperative behavior. Furthermore, Anderson et al. (2004) reported contradictory effects of the participation in voluntary activities on the behavior in a public goods game. Carpenter et al. (2004) used a somewhat similar approach as we did. They argued that the term social capital is poorly defined and categorizes two distinct aspects, namely behavioral social capital (the propensities of individuals to trust, cooperate, and punish other individuals who act to establish and maintain pro-social norms of behavior) and associational social capital (the community-level networks among individuals that lead to efficient outcomes when contracts are hard to enforce). However, their results were mixed: in Bangkok, those who claimed to have been active in the community also cooperated more in a repeated voluntary contribution mechanism; whereas, in Ho Chi Minh City, the relation was reversed.

\section{The Basic Setup of the Experiment}

Our research design builds on the experiment developed by Gächter and Herrmann (2007) and had two separate parts. Part I was a standard, linear, one-shot public goods experiment (the voluntary contribution mechanism) that allowed us to study determinants of cooperation. Part II was a voluntary contribution mechanism augmented by an individual's possibility to punish other group members. The existence of the punishment option permits an analysis of cooperative behavior in the presence of a decentralized norm enforcement device, but more importantly, it provides the opportunity to assess the determinants of the use of norm enforcement in social dilemmas.

Specifically, let $I=\{1,2, \ldots, n\}$ denote a group of $n$ subjects which interact in a oneshot, simultaneous public goods game without punishment (Part I). Individual $i \in I$ receives an endowment $E$, which can be allocated either to a private good or to a public good. The voluntary contribution of individual $i$ to the public good $c_{i}$ must satisfy $0 \leq c_{i} \leq E$. Let $C$ denote the sum of all group members' contributions (i.e., $C=\sum_{j=1}^{n} c_{j}$ ). The contribution of individual member $i$ 's payoff is given by

$$
\pi_{i}=E-c_{i}+\gamma C
$$


The marginal per capita return (MPCR) from investing in the public good is denoted by $\gamma$, which satisfies $0<\gamma<1<n \gamma$, meaning that the self-interested choice and the socially optimal one are in conflict. The parameters in our experimental sessions were chosen as follows: group size $n=3$, endowment of $E=20$ guilders (the experimental currency unit), and MPCR $\gamma=0.5$. The contribution $c_{i}$ was restricted to integers to facilitate calculations during the experiment.

In the public goods game with punishment (Part II), subjects can punish other group members individually, after they have received information on their contribution levels. The game is now a two-stage game, with a simultaneous contribution stage followed by a simultaneous punishment stage. Employing the punishment technology used by Gächter and Herrmann (2007), the unit cost per punishment point is 1 guilder, and one unit of punishment results in a deduction of 3 guilders in terms of payoff for the member who receives the punishment. ${ }^{6}$ Each subject can assign a maximum of 10 punishment points to any other member in the group.

Taking into account the monetary consequences of the punishment stage yields the following payoff function for a group member $i$

$$
\pi_{i}=E-c_{i}+\gamma C-\sum_{k \neq i} p_{i k}-3 \sum_{h \neq i} p_{h i},
$$

where $p_{i k}$ denotes the number of punishment points assigned by member $i$ to member $k$, and $p_{h i}$ is the number of punishment points that member $i$ received from member $h$.

Assuming rationality and selfishness, we should neither observe any voluntary contributions in both parts of the experiment nor any assignment of punishment points in the public goods game with punishment, according to the sub-game perfect equilibrium. It is important to emphasize that there is no strategic reason to cooperate in the first part of the experiment. The details of the interaction in the second part were only made public after all decisions in Part I had been recorded. Subjects in the experiment knew from the beginning that there would be a second part and that it would be unrelated to the first part. Results from this first part were only revealed after the end of Part II. Groups were assembled anew in Part

\footnotetext{
6 We are not studying the influence of structural variables, such as the size of the marginal per capita return or the strength of the punishment mechanism in this paper (Falk et al. 2005; Sutter et al. 2006). Previous experiments have shown that punishment behavior follows the law of demand, i.e. the quantity of punishment declines with a rising price of punishment (Anderson and Putterman 2006; Carpenter 2007).
} 
II under the condition that no single subject met again during the experiment, and this was common knowledge.

Obviously, there was also no strategic reason to punish in Part II because of the oneshot nature of the interaction. General findings from a multitude of experiments show, however, that subjects increase their contributions when facing such a punishment opportunity and punish each other both in one-shot experiments as well as in multi-period experiments with stranger matching (e.g., Fehr and Gächter 2000; Gächter et al. 2004; Gächter and Herrmann 2007; Herrmann et al. 2008).

\section{Details of the Experiment Design}

In each high school, the experiment consisted of a single session with 60 participants (except in the colored community, where there were 69 participants) to avoid contagious effects by word-of-mouth communication between sessions. The subjects were recruited by public announcements at the schools. In both African schools (which served a larger area than the communities we focused on), we directed the announcement only to those in our target communities. We conducted the experiment in English, which is also the language used in the schools. In order to ensure complete understanding, Afrikaans-speaking helpers were used in the white and colored schools and Xhosa-speaking assistants in the African schools. We used assembly halls to guarantee anonymity and to keep the subjects far apart from each other. When they arrived for the experiment, subjects were randomly assigned a seat. The experiment was conducted with paper and pen.

At the beginning, participants learned that the experiment will consist of two independent parts and received instructions for Part I. ${ }^{7}$ Subjects were given time to read the instructions, which were also read aloud by the instructor. Next, participants took a written quiz that was designed to test their understanding of the experiment, and afterwards, correct answers and solutions were explained on the blackboard. Finally, to make sure that everyone understood the experiment before starting with Part I, we dedicated a significant amount of time to answering in private any remaining questions that subjects had. All submitted decisions were anonymous and subjects were aware of this fact. Communication among participants during the experiment was strictly forbidden.

\footnotetext{
7 The instructions are included in Appendix II. They were framed in neutral terms and did not contain any loaded expressions, such as "punishment".
} 
We followed a similar procedure before Part II, although we focused on explaining how punishment worked and, again, included a quiz, followed by time to ask questions in private. As already noted, we re-clustered subjects into new groups before Part II, and they were clearly informed of this procedure. ${ }^{8}$ After their contributions in Part II had been handed in, we asked subjects what they believed the average contributions of the other group members were to the public goods in both Part I and Part II. We then continued with the second stage of Part II, which included the possibility of punishing other members of their own group. Each member of the group was informed about the contributions of the other two members to the public good in Part II (but no information on behavior in Part I was revealed).

After completing Part II, a post-experiment questionnaire to obtain socio-economic, background and attitudinal variables was handed out and, as a final part of the experiment, everybody was paid privately in cash checks. ${ }^{9}$ We calibrated the experiment, partly based on a small pilot study, such that the participants on average would earn quite a bit more than if they had spent the time working. One guilder in the experiment was exchanged for 1.5 South African rand (ZAR). ${ }^{10}$

\section{Subject Pool}

The experiment was conducted at four different high schools in Cape Town, which were carefully selected to capture differences in socio-economic strata in the South African society. Table 1 gives some background information obtained from the Cape Area Panel Study for Young Adults (Lam et al. 2006) and the 2001 South African census (Stats SA 2003) on the communities in the catchment areas of each of the four selected high schools. Table 1 clearly shows that individuals in the white community were better off than those from the colored community; and both of these were lagged significantly by the two African communities with respect to income, education, and employment of parents, as well as housing standards.

\footnotetext{
8 In the instructions for Part II, we wrote, "Note, however, that now you will be in a group with two other people than before" [bold used in instructions as shown], i.e. in a new group with two different people than in Part I."

9 We used cash checks instead of cash for security reasons.

10 The exchange rate at the time of the experiment was ZAR $6.10=$ US $\$ 1$.
} 
Table 1. Descriptive Statistics of Community Data.

\begin{tabular}{|c|c|c|c|c|c|}
\hline & Source & White & Colored & $\begin{array}{c}\text { African } \\
\text { permanent }\end{array}$ & $\begin{array}{c}\text { African } \\
\text { informal }\end{array}$ \\
\hline $\begin{array}{l}\text { Monthly per capita income (in } \\
\text { ZAR) }\end{array}$ & CAPS & 3750 & 1100 & 374 & 288 \\
\hline Households in poverty & Census & $13.00 \%$ & $14.47 \%$ & $47.56 \%$ & $45.95 \%$ \\
\hline $\begin{array}{l}\text { Mothers with high school } \\
\text { certificate }\end{array}$ & CAPS & $92.30 \%$ & $46.15 \%$ & $12.31 \%$ & $15.15 \%$ \\
\hline $\begin{array}{l}\text { Fathers with high school } \\
\text { certificate }\end{array}$ & CAPS & $83.33 \%$ & $53.85 \%$ & $20.69 \%$ & $16.59 \%$ \\
\hline Mothers working & CAPS & $69.23 \%$ & $68.75 \%$ & $23.44 \%$ & $29.10 \%$ \\
\hline Father working & CAPS & $100.00 \%$ & $84.00 \%$ & $46.43 \%$ & $50.94 \%$ \\
\hline Living in permanent building & CAPS & $100.00 \%$ & $86.20 \%$ & $68.40 \%$ & $40.50 \%$ \\
\hline Piped water in the house & CAPS & $100.00 \%$ & $97.94 \%$ & $66.72 \%$ & $27.46 \%$ \\
\hline
\end{tabular}

Note: Summary statistics are percentages or averages.

Sources: Cape Area Panel Study (CAPS) for Young Adults, 2006 (Lam et al. 2006), and the South African Census 2001 (SA

Stats 2003). Descriptive data have been obtained for the communities that serve as catchment areas for the schools in our experiments.

The information is also helpful in illustrating that there are, indeed, pertinent differences in the permanency of housing infrastructure between the African permanent and African informal communities in our sample. The majority of housing in the latter community was informal shacks without in-house drinking water.

\section{Experimental Results}

We begin this section with an overview of our results in each of the four communities. Table 2 summarizes the average levels of contributions in both public goods games, and Table 3 shows the structure of punishment among the groups. ${ }^{11}$ In addition, these two tables also include more detailed analyses: we calculated the proportion of zero contribution and punishment, as well as conditional contribution (i.e., the average contribution, given that a positive amount was contributed) and conditional punishment levels (i.e., the average punishment level, given that a positive punishment level was chosen). Data from the public goods experiment without punishment (Part I) show that subjects in the white community contributed the least — on average only 6.88 guilders (34.4 percent of the endowment) -

11 A complete table of descriptive statistics for the variables used in the results section is provided in appendix I (table A1). 
compared to the contribution levels of 8.51 guilders by the colored community (42.6 percent), 9.34 guilders by the African permanent community (46.7 percent), and 11.27 guilders by the African informal community (56.4 percent).

Table 2. Average Levels of Contribution to the Public Goods, Proportion of FreeRiders, and Conditional Average Levels of Contribution.

\begin{tabular}{lrcc|ccc}
\hline & \multicolumn{3}{c}{$\begin{array}{c}\text { Average contribution: } \\
\text { No punishment (Part I) }\end{array}$} & \multicolumn{2}{c}{$\begin{array}{c}\text { Average contribution: } \\
\text { With punishment (Part II) }\end{array}$} \\
\cline { 2 - 7 } & $\begin{array}{l}\text { Total } \\
\text { contrib. }\end{array}$ & $\begin{array}{c}\text { Proportion of } \\
\text { zero contrib. }\end{array}$ & $\begin{array}{c}\text { Contrib. } \text { if } \\
\text { contrib. }>\mathbf{0}\end{array}$ & $\begin{array}{c}\text { Total } \\
\text { contrib. }\end{array}$ & $\begin{array}{c}\text { Proportion of } \\
\text { zero contrib. }\end{array}$ & $\begin{array}{c}\text { Contrib. if } \\
\text { contrib. }>\text { 0 }\end{array}$ \\
\hline White & 6.88 & 0.30 & 9.83 & 8.25 & 0.17 & 10.69 \\
Colored & 8.51 & 0.16 & 10.16 & 8.85 & 0.20 & 11.33 \\
African permanent & 9.34 & 0.12 & 10.67 & 10.70 & 0.06 & 11.04 \\
African informal & 11.27 & 0.10 & 12.55 & 11.37 & 0.11 & 12.67 \\
\hline
\end{tabular}

The null hypothesis that contributions in two independent communities are drawn from the same distribution is rejected at a 5 percent significance level, using a WilcoxonMann-Whitney test, except for the following pair-wise comparisons: 1) colored and African permanent, and 2) African permanent and African informal (see table A2 in appendix). A Kruskal-Wallis test confirms with $p<0.01$ that the contribution levels in the four communities are not equal. Our figures can be compared to Gächter and Herrmann (2007), who used a $2 * 2$ design, where subjects differed in age (young or mature) and location (urban and rural). In their urban and young sample, the average contribution level was 37 percent, while in the other three groups, the averages ranged from 50.5 percent to 53.5 percent.

Introducing punishment possibilities in Part II resulted in an increase in the contributions to the public good in all four communities, which is in line with most research (with the exception of Gächter and Herrmann 2007, 2009 as well as Herrmann et al. 2008). The average increase was largest in the white community, where the average contribution increased to 8.25 (41.2 percent of the endowment), equivalent to an increase by almost 7 percentage units, or 19.9 percent. In the other three schools, the increases were more modest: 8.85 (44.2 percent), 10.7 (53.5 percent), and 11.37 (56.8 percent) for colored, African permanent, and African informal, respectively. The Kruskal-Wallis test that compares the four groups still indicates a significant difference $(p=0.02)$. However, we cannot reject the null hypothesis of equal contributions in Part I and Part II at a 5 percent significance level in the four communities using a Wilcoxon-signed-ranks test, except for the white community (see table A4 in appendix). 
In Part II, we can also analyze the punishment stage. Although subjects from the white and the colored communities, on average, contributed less to the public good, punishment was also lower among them than among the subjects in the two African communities (as shown in table 3). We can reject the null hypothesis of an equal amount of punishment in pair-wise tests using Wilcoxon-Mann-Whitney tests at a 5 percent significance level, except for the following pair-wise comparisons: 1) white and colored, and 2) African permanent and African informal (see table A5 in appendix). The Kruskal-Wallis test is highly significant $(p<0.001)$, rejecting the hypothesis that the four groups are equal.

Figure 1 displays the structure of the punishment points assigned to other members in the group in relation to the difference between the contribution of the punisher and the contribution of the punished. A negative number on the $\mathrm{x}$-axis indicates that the punished subject contributed less than the punisher, and vice versa. Although there is a tendency of increased punishment of others when the negative difference between one's own contribution and that of others is increasing, this tendency is not too pronounced.

For all groups, there is some anti-social punishment, but in the African communities, there seems to be a substantial amount of this misdirected punishment. In table 3, we calculate the degree of anti-social punishment, which is measured as the ratio between mean punishment of non-negative deviations and mean punishment of negative deviations. It ranged from 0.42 to 0.53 for three of our four communities, with the African permanent group standing out with a degree of 0.94, which is higher than any of the figures in Gächter and Herrmann (2007). Their highest was in the urban-and-mature group with 0.78. Note that the difference between the two African communities in terms of punishment behavior indicates that there seem to be fundamental differences between the two communities. ${ }^{12}$

12 A more detailed analysis of anti-social or spiteful punishment is available on request. 
Figure 1. The Structure of Punishment.

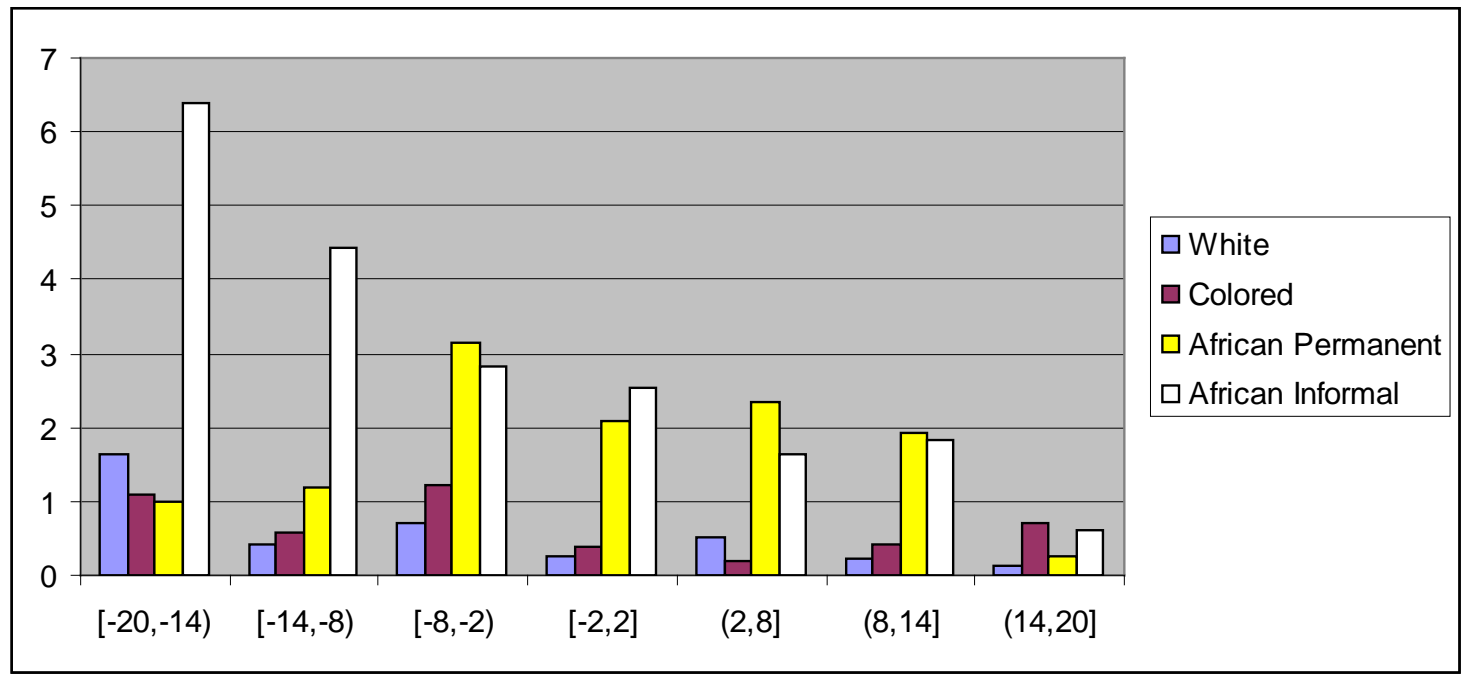

Table 3. Structure of Punishment.

\begin{tabular}{lcccc}
\hline & Punishment & $\begin{array}{c}\text { Proportion of } \\
\text { punishment }\end{array}$ & $\begin{array}{c}\text { Conditional } \\
\text { punishment }\end{array}$ & $\begin{array}{c}\text { Degree of spiteful (anti- } \\
\text { social) punishment }\end{array}$ \\
\cline { 2 - 5 } White & 0.49 & 0.75 & 1.96 & 0.42 \\
Colored & 0.62 & 0.76 & 2.58 & 0.46 \\
African permanent & 2.09 & 0.48 & 4.03 & 0.94 \\
African informal & 2.64 & 0.41 & 4.44 & 0.53 \\
\hline & Note: Degree of spiteful punishment is the ratio between the average punishment of non-negative deviators and the average \\
punishment of negative deviators.
\end{tabular}

Table 4 gives the average total net earnings in guilders in the two parts of the experiment at the community level. As is obvious from the results on contributions and punishment, the participants of the African communities earned more in Part 1. However, the higher levels of punishment among the African communities (which has a negative impact on the earnings of both punishers and the punished) resulted in their earnings being substantially lower than for the white and colored groups in Part II. On the other hand, the white and colored communities earned, on average, similar amounts in Part I and Part II. 
Table 4. Total Net Earnings in Guilders.

\begin{tabular}{lcc}
\hline & Part I & Part II \\
\hline White & 23.44 & 20.19 \\
Colored & 24.07 & 19.39 \\
African permanent & 25.03 & 7.90 \\
African informal & 25.91 & 4.48 \\
\hline
\end{tabular}

\subsection{Determinants of Cooperation}

We study the determinants of cooperative behavior by controlling for demographic and social background variables in an econometric analysis. First, we analyze which factors explain the amounts contributed to the public good in Part I and Part II. Then, we examine what determined the punishment points assigned to other subjects in the group (section 6.2). In all cases, we ran Tobit regressions, since the dependent variables were censored on both sides (applying OLS, however, does not change our main results).

In table 5, we analyze what determined the amount contributed to the public good in Part I. The first regression (model (1)) only includes the dummy variables for the different communities (where the white community was the reference group) and the beliefs of the average contribution of other group members to the public goods. In the other regressions, we gradually include basic socio-demographic variables, such as gender, age and age squared, and a battery of other socio-economic and background variables as specified above.

Regardless of the model specification, beliefs about the contributions of others were a consistent determinant of cooperative behavior, much in the spirit of the empirical evidence on conditional cooperation (e.g., Fischbacher et al. 2001; Croson 2007; Fischbacher and Gächter 2009; Gächter and Herrmann 2009). ${ }^{13}$ We also found that being female increased contributions significantly and consistently in our subject pool. Croson and Gneezy (2009) argued in their authoritative overview that women are more sensitive to experimental details

13 Since we elicited beliefs on others' contributions after the decision on one's own contribution, it is possible that belief responses have been influenced by prior decisions. We are not aware of any paper that systematically compares ex-ante with ex-post belief elicitation in a public goods game with a public goods game that does not elicit beliefs on others' contributions. 
than men. It is difficult to interpret what that means in our context. Consequently, we do not want to over-interpret our results regarding gender differences. Furthermore, age and age squared did not show up significantly in any of the regression models, which is not surprising, given the small variation in our subject pool.

Another fact emerging from table 5 seems more striking and has an important implication: while it appeared at first sight from the dummy variables for the two African communities that contributions by these two groups were significantly higher compared to the white community, controlling for several individual socio-demographic variables discussed above and a few background variables expounded in greater detail in the following paragraph rendered the coefficients for the community dummies insignificant (see model (4)).

The background variables we use are 1) attitudinal measures of trust (trust in schoolmates), 2) behavioral measures of an individual's level of integration into own peer group and community (social integration), and 3) behavioral measures on norm violation and norm enforcement (community crime and household violence). The choice of these background variables reflects their importance in influencing cooperative behavior and norm development as well as norm enforcement. Trust, as the first variable, has been shown to be connected to cooperative behavior (e.g., Gächter et al. 2004). It seems very likely that trusting is related to conditional cooperation in the sense that cooperating based on the expected cooperation of others requires a certain level of trust in others. The second set of variables that capture social integration is intended to get a grip on the role of an individual's cooperative norms in daily life. The underlying hypothesis is that students who are active in their community have a stronger attachment to cooperative norms than less active students. Finally, variables on norm violation and norm enforcement should capture the daily experience of students in these two domains. Again, we expect that students who observe norm violations in their daily lives more often are more likely to punish and more likely to punish harshly.

More specifically, we used a 6-point scale trust measure with questions similar to the World Values Survey; a dummy variable for an individual's participation in school organizations; a continuous variable for the number of times the subject's household was a victim of housebreaking over the last year; a variable regarding psychological violence (i.e. swearing)of parents or adults in the household towards the subject on a scale from 1 (occurs 
never) to 5 (occurs very often) ${ }^{14}$; and a household reading index, which is supposed to capture household literacy and household inclination to education. The latter was just the sum of dummy variables from the answers to the following four questions: 1) Is there is a daily newspaper in your household?; 2) Does your household own an encyclopedia?; 3) Is there a dictionary in your house?; and 4) Does the family own more than 50 books? ${ }^{15}$ (All these variables were self-reported by subjects in the post-experimental questionnaire.)

A look at models (3), (4), and (5) reveals that trust in schoolmates on the 6-point scale has the expected positive, significant and robust effect on voluntary contributions. This is in line with related studies, but still remarkable because we also control for expectations. Expectations should capture at least part, if not all of the aspects of trust in others. Given our data, it obviously did not, since a higher level of trust increases contributions in addition to the conditional cooperation aspect of higher contributions with higher expectations on the contributions of others.

Our variable for social integration, however, does not come out significant. We have hypothesized that people who are (more) involved in real-world organizations tend to be more cooperative than others, but that does not seem to be the case when using the variable participate in school organization. This can be the consequence of at least three possibilities: first, there is actually only a weak relationship between social integration and individual behavior in public goods experiments; second, the cooperative norm that we expected to be related with social integration does only work in combination with an embedded enforcement mechanism; and third, we were not able to come up with the right proxy for it. ${ }^{16}$

The two variables community crime and household violence are both far from significant in any of the models. This is not surprising at all, given that it is difficult to imagine significant links between them and the voluntary contribution to a public good. We included these two variables in the regressions in table 5 for means of comparison. We will use them again in section 6.2 when we study norm enforcement.

\footnotetext{
14 The exact wording was: "How often did a parent, stepparent, or adult living in your home swear at you or put you down when you where younger?”

15 A normalization procedure was performed on the household reading index that entails subtraction of the mean and division by the standard deviation.

16 However, if we substitute the variable by other membership variables such as political party, voluntary nonprofit organization, religious organization and sport clubs memberships or participation in art (such as choir and orchestra), our results do not change.
} 
Table 5. Determinants of Contributions in Part I.

\begin{tabular}{|c|c|c|c|c|c|}
\hline \multirow[b]{2}{*}{$\begin{array}{l}\text { Independent variable: } \\
\text { Contributions in Part I }\end{array}$} & \multicolumn{5}{|c|}{ Model } \\
\hline & (1) & (2) & (3) & (4) & (5) \\
\hline \multirow{2}{*}{ Expectations } & $0.30 *$ & $0.28 *$ & $0.25 *$ & $0.28 *$ & $0.27 *$ \\
\hline & $(0.16)$ & $(0.16)$ & $(0.15)$ & $(0.15)$ & $(0.15)$ \\
\hline \multirow{2}{*}{ Colored } & 2.63 & 2.03 & 0.08 & -0.66 & - \\
\hline & $(1.67)$ & (1.69) & $(1.71)$ & $(1.77)$ & \\
\hline \multirow{2}{*}{ African permanent } & $2.97^{*}$ & 2.73 & -0.36 & -2.99 & - \\
\hline & $(1.76)$ & $(1.76)$ & (1.95) & $(2.27)$ & \\
\hline \multirow{2}{*}{ African informal } & $5.71 * * *$ & $5.22 * * *$ & $3.83^{* *}$ & 1.50 & - \\
\hline & $(1.73)$ & $(1.74)$ & $(1.83)$ & $(2.12)$ & \\
\hline \multirow{2}{*}{ Female } & - & $2.42 *$ & $3.47 * * *$ & $3.28 * *$ & $3.41 * *$ \\
\hline & & $(1.36)$ & $(1.36)$ & $(1.37)$ & $(1.35)$ \\
\hline \multirow{2}{*}{ Age } & - & - & 14.62 & 11.09 & 8.56 \\
\hline & & & $(13.15)$ & $(13.02)$ & $(12.92)$ \\
\hline \multirow{2}{*}{ Age $^{2}$} & - & - & -0.35 & -0.25 & -0.19 \\
\hline & & & $(0.38)$ & $(0.37)$ & $(0.37)$ \\
\hline \multirow{2}{*}{ Trust: in schoolmates } & - & - & $0.84 * *$ & $0.78 * *$ & $0.68 * *$ \\
\hline & & & $(0.34)$ & $(0.34)$ & $(0.33)$ \\
\hline \multirow{2}{*}{$\begin{array}{l}\text { Social integration: Participate } \\
\text { in school organizations }\end{array}$} & - & - & - & -0.22 & -0.28 \\
\hline & & & & $(1.14)$ & $(1.16)$ \\
\hline \multirow{2}{*}{ Community crime: Housebreaking } & - & - & - & 0.10 & 0.09 \\
\hline & & & & $(0.20)$ & $(0.20)$ \\
\hline \multirow{2}{*}{ Household violence: Swearing } & - & - & - & 0.26 & 0.27 \\
\hline & & & & $(0.48)$ & $(0.64)$ \\
\hline \multirow{2}{*}{ Household reading index } & - & - & - & $-1.84 * *$ & $-1.74 * * *$ \\
\hline & & & & $(0.74)$ & $(0.64)$ \\
\hline \multirow{2}{*}{ Constant } & $3.86 * *$ & 2.63 & -146.8 & -113.9 & -89.0 \\
\hline & $(1.61)$ & $(1.75)$ & $(114.25)$ & $(113.2)$ & $(112.3)$ \\
\hline No. of observations & 243 & 243 & 243 & 238 & 238 \\
\hline Log-likelihood & -680.9 & -679.3 & -669.1 & -649.8 & -653.3 \\
\hline LR chi ${ }^{2}$ & $15.9 * * *$ & $19.1^{* * *}$ & $39.6^{* * *}$ & $47.1^{* * *}$ & $40.7^{* * *}$ \\
\hline Pseudo $\mathrm{R}^{2}$ & 0.012 & 0.014 & 0.029 & 0.035 & 0.030 \\
\hline
\end{tabular}


Finally, the household reading index that should capture the household's educational background always significantly reduced the contribution level in models (4) and (5).

Our results do not change at all when we control for the self-reported allowances (pocket-money) and/or weekly part-time work outside school as a proxy for income. We explicitly distinguished between part-time work and (unpaid) household assistance in that respect. As sensitivity tests, we also substituted trust in schoolmates for general trust, the dummy variable school integration for the number of organizations in which the participant claimed membership, the variable housebreaking for "rape" (and the dummies by the number of instances over the last twelve months), as well as psychological violence in the household (household violence) for physical violence (corporal punishment). None of our conclusions changed; significant coefficients remained significant and non-significant coefficients stayed non-significant.

There is probably one general lesson to be drawn from these results: at least with non-standard subject pools such as ours, it seems important to control for a few sociodemographic variables (and perhaps even some background variables) in order to avoid drawing premature conclusions. If we had just relied on the school dummies, we would have interpreted our results in terms of "cultural" community differences instead of being more cautious and concluding that they could also partly be driven by socio-demographic variables or social background variables. This holds especially for the African permanent community, whereas the higher level of contributions of the African informal community as such seems to be the more persistent effect.

Table 6 presents the determinants of contributions to the public good in Part II of the experiment, using the same regression models as in Part I. The general picture is very similar in the two parts, which is an indication that our results seem to be robust. In particular, the predictive power of expectations and the significance for the household reading index become stronger.

The trust variables are completely insignificant in table 6. One straightforward explanation is that, in view of the punishment option that followed the contribution phase in Part II, trust was simply not important any more for the level of contributions because subjects had a norm enforcement device at hand. Also the gender effect vanishes. It could be that men react more strongly to the introduction of the punishment option than do women, but since we did not start out from such a hypothesis the conclusion would not be well-founded. In any case, men increased their contributions more from Part I to Part II than women did. 
Table 6. Determinants of Contributions in Part II.

\begin{tabular}{|c|c|c|c|c|c|}
\hline \multirow[b]{2}{*}{$\begin{array}{l}\text { Independent variable: } \\
\text { Contributions in Part II }\end{array}$} & \multicolumn{5}{|c|}{ Model } \\
\hline & (1) & (2) & (3) & (4) & (5) \\
\hline Expectations & $\begin{array}{c}0.33^{* * *} \\
(0.09)\end{array}$ & $\begin{array}{c}0.33^{* * *} \\
(0.09)\end{array}$ & $\begin{array}{c}0.34^{* * *} \\
(0.09)\end{array}$ & $\begin{array}{c}0.34^{* * *} \\
(0.09)\end{array}$ & $\begin{array}{c}0.35^{* * *} \\
(0.09)\end{array}$ \\
\hline Colored & $\begin{array}{l}1.14 \\
(1.46)\end{array}$ & $\begin{array}{c}0.98 \\
(1.49)\end{array}$ & $\begin{array}{l}-0.32 \\
(1.56)\end{array}$ & $\begin{array}{l}-1.16 \\
(1.62)\end{array}$ & - \\
\hline African permanent & $\begin{array}{l}3.65^{* *} \\
(1.52)\end{array}$ & $\begin{array}{l}3.57 * * \\
(1.53)\end{array}$ & $\begin{array}{c}1.21 \\
(1.76)\end{array}$ & $\begin{array}{l}-1.28 \\
(2.07)\end{array}$ & - \\
\hline African informal & $\begin{array}{c}4.06^{* * *} \\
(1.50)\end{array}$ & $\begin{array}{c}3.92^{* * *} \\
(1.53)\end{array}$ & $\begin{array}{c}2.32 \\
(1.66)\end{array}$ & $\begin{array}{c}0.27 \\
(1.93)\end{array}$ & - \\
\hline Female & - & $\begin{array}{l}0.59 \\
(1.19)\end{array}$ & $\begin{array}{c}1.20 \\
(1.23)\end{array}$ & $\begin{array}{c}1.24 \\
(1.24)\end{array}$ & $\begin{array}{c}1.13 \\
(1.20)\end{array}$ \\
\hline Age & - & - & $\begin{array}{c}7.58 \\
(11.96)\end{array}$ & $\begin{array}{c}8.24 \\
(11.86)\end{array}$ & $\begin{array}{c}5.94 \\
(11.66)\end{array}$ \\
\hline Age $^{2}$ & - & - & $\begin{array}{l}-0.18 \\
(0.34)\end{array}$ & $\begin{array}{l}-0.20 \\
(0.34)\end{array}$ & $\begin{array}{l}-0.14 \\
(0.33)\end{array}$ \\
\hline Trust: in schoolmates & - & - & $\begin{array}{l}-0.06 \\
(0.31)\end{array}$ & $\begin{array}{l}-0.12 \\
(0.31)\end{array}$ & $\begin{array}{l}-0.16 \\
(0.30)\end{array}$ \\
\hline $\begin{array}{l}\text { Social integration: Participate } \\
\text { in school organizations }\end{array}$ & - & - & - & $\begin{array}{c}0.08 \\
(1.05)\end{array}$ & $\begin{array}{c}0.15 \\
(1.04)\end{array}$ \\
\hline Community crime: Housebreaking & - & - & - & $\begin{array}{c}0.24 \\
(0.18)\end{array}$ & $\begin{array}{c}0.24 \\
(0.18)\end{array}$ \\
\hline Household violence: Swearing & - & - & - & $\begin{array}{c}0.20 \\
(0.44)\end{array}$ & $\begin{array}{c}0.22 \\
(0.44)\end{array}$ \\
\hline Household reading index & - & - & - & $\begin{array}{l}-1.17^{*} \\
(0.68)\end{array}$ & $\begin{array}{l}-1.14^{* *} \\
(0.57)\end{array}$ \\
\hline Constant & $\begin{array}{l}3.55^{* *} \\
(1.60)\end{array}$ & $\begin{array}{l}3.23^{* * *} \\
(1.73)\end{array}$ & $\begin{array}{c}-73.7 \\
(104.0)\end{array}$ & $\begin{array}{c}-77.9 \\
(103.2)\end{array}$ & $\begin{array}{c}-57.0 \\
(101.4)\end{array}$ \\
\hline No. of observations & 243 & 243 & 243 & 238 & 238 \\
\hline Log-likelihood & -698.9 & -698.7 & -695.3 & -679.5 & -680.3 \\
\hline LR chi ${ }^{2}$ & $21.4^{* * *}$ & $21.7^{* * *}$ & $28.6^{* * *}$ & $32.6 * *$ & $31.1^{* * *}$ \\
\hline Pseudo $\mathrm{R}^{2}$ & 0.015 & 0.015 & 0.020 & 0.023 & 0.022 \\
\hline
\end{tabular}




\subsection{Determinants of Punishment}

Table 7 presents a basic set of Tobit regressions for assigned punishment points. Again, OLS yields quite similar results. Interestingly, punishment is almost uniquely explained by community dummy variables, where punishment levels in the African permanent and the African informal communities are significantly higher than in the white group. As expected, a positive deviation from one's own contribution has a negative and significant effect on punishment, while a negative deviation from one's own contribution elicits significantly higher levels of punishment. In contrast, gender did not influence punishment significantly. Age and age squared were again insignificant.

Table 7. Determinants of Punishment I.

\begin{tabular}{|c|c|c|c|c|}
\hline \multirow[b]{2}{*}{$\begin{array}{l}\text { Dependent variable: } \\
\text { Punishment points assigned }\end{array}$} & \multicolumn{4}{|c|}{ Model } \\
\hline & (1) & (2) & (3) & (4) \\
\hline \multirow{2}{*}{$\begin{array}{l}\text { Positive deviation from own } \\
\text { contribution }\end{array}$} & $-0.13^{*}$ & $-0.12 * *$ & $-0.12 *$ & $-0.11 *$ \\
\hline & $(0.07)$ & $(0.06)$ & $(0.06)$ & $(0.06)$ \\
\hline \multirow{2}{*}{$\begin{array}{l}\text { Absolute negative deviation from } \\
\text { own contribution }\end{array}$} & $0.10 *$ & $0.11^{* *}$ & $0.11^{* *}$ & $0.10^{*}$ \\
\hline & $(0.06)$ & $(0.05)$ & $(0.05)$ & $(0.06)$ \\
\hline \multirow{2}{*}{ Colored } & - & 0.19 & -0.18 & - \\
\hline & & $(0.79)$ & $(0.84)$ & \\
\hline \multirow{2}{*}{ African permanent } & - & $4.13^{* * *}$ & $3.47 * * *$ & - \\
\hline & & $(0.77)$ & $(0.89)$ & \\
\hline \multirow{2}{*}{ African informal } & - & $5.09 * * *$ & $4.60 * * *$ & - \\
\hline & & $(0.77)$ & $(0.82)$ & \\
\hline \multirow{2}{*}{ Age } & - & - & -1.15 & -5.90 \\
\hline & & & $(5.76)$ & (6.16) \\
\hline \multirow{2}{*}{ Age $^{2}$} & - & - & 0.04 & 0.20 \\
\hline & & & $(0.16)$ & $(0.18)$ \\
\hline \multirow{2}{*}{ Female } & - & - & 0.60 & $1.27 *$ \\
\hline & & & $(0.61)$ & $(0.64)$ \\
\hline \multirow[t]{2}{*}{ Constant } & $-1.43 * * *$ & $-3.67 * * *$ & 3.17 & 39.76 \\
\hline & $(0.53)$ & $(0.75)$ & (50.12) & (53.61) \\
\hline Observations & 486 & 486 & 486 & 486 \\
\hline Log likelihood & -735.5 & -697.5 & -696.3 & -724.9 \\
\hline LR chi $^{2}$ & $12.9 * * *$ & $88.79 * * *$ & $91.14^{* * *}$ & $33.88^{* * *}$ \\
\hline Pseudo $\mathrm{R}^{2}$ & 0.009 & 0.060 & 0.060 & 0.023 \\
\hline
\end{tabular}


Table 8. Determinants of Punishment II.

\begin{tabular}{|c|c|c|c|}
\hline \multirow[b]{2}{*}{$\begin{array}{l}\text { Dependent variable: } \\
\text { Punishment points assigned }\end{array}$} & \multicolumn{3}{|c|}{ Model } \\
\hline & (1) & (3) & (3) \\
\hline \multirow{2}{*}{$\begin{array}{l}\text { Positive deviation from own } \\
\text { contribution }\end{array}$} & $-0.11 *$ & $-0.13 * *$ & $-0.13^{* *}$ \\
\hline & $(0.06)$ & $(0.06)$ & $(0.06)$ \\
\hline \multirow{2}{*}{$\begin{array}{l}\text { Absolute negative deviation from own } \\
\text { contribution }\end{array}$} & $0.11 * *$ & $0.11^{*}$ & $0.10^{*}$ \\
\hline & $(0.05)$ & $(0.05)$ & $(0.06)$ \\
\hline \multirow{2}{*}{ Colored } & -0.10 & -0.74 & - \\
\hline & $(0.83)$ & $(0.87)$ & \\
\hline \multirow{2}{*}{ African permanent } & $3.69 * * *$ & $2.50 * *$ & - \\
\hline & $(0.89)$ & $(1.05)$ & \\
\hline \multirow{2}{*}{ African informal } & $4.99 * * *$ & $3.92 * * *$ & - \\
\hline & $(0.85)$ & $(0.97)$ & \\
\hline \multirow{2}{*}{ Age } & -0.65 & -1.13 & -6.77 \\
\hline & $(5.74)$ & (5.73) & $(5.95)$ \\
\hline \multirow{2}{*}{ Age $^{2}$} & 0.03 & 0.04 & 0.21 \\
\hline & $(0.16)$ & $(0.16)$ & $(0.17)$ \\
\hline \multirow{2}{*}{ Female } & 0.60 & 0.34 & 0.64 \\
\hline & $(0.61)$ & $(0.62)$ & $(0.63)$ \\
\hline \multirow{2}{*}{ Trust in schoolmates } & $0.31 * *$ & $0.32 * *$ & 0.07 \\
\hline & $(0.15)$ & $(0.15)$ & $(0.15)$ \\
\hline \multirow{2}{*}{$\begin{array}{l}\text { Social integration: Participate in } \\
\text { school organizations }\end{array}$} & - & -0.16 & 0.12 \\
\hline & & $(0.52)$ & $(0.54)$ \\
\hline \multirow{2}{*}{ Community crime: Housebreaking } & - & -0.14 & -0.02 \\
\hline & & $(0.09)$ & $(0.09)$ \\
\hline \multirow{2}{*}{ Household violence: Swearing } & - & $0.41 *$ & $0.53 * *$ \\
\hline & & $(0.22)$ & $(0.23)$ \\
\hline \multirow{2}{*}{ Household reading index } & - & $-0.89 * * *$ & $-1.72 * * *$ \\
\hline & & $(0.35)$ & $(0.32)$ \\
\hline \multirow{2}{*}{ Constant } & -2.94 & 2.61 & 51.77 \\
\hline & $(50.06)$ & (49.95) & (51.87) \\
\hline No. of observations & 486 & 476 & 476 \\
\hline Log-likelihood & -694.1 & -673.4 & -691.5 \\
\hline LR chi ${ }^{2}$ & $95.6^{* * *}$ & $108.5^{* * *}$ & $72.3^{* * *}$ \\
\hline Pseudo $\mathrm{R}^{2}$ & 0.060 & 0.075 & 0.050 \\
\hline
\end{tabular}


In table 8, we control for the same social background variables as in the regression models for cooperation. Even after doing so, both African community dummies remain significant, although some of the social background variables are in fact also important in explaining punishment behavior. Including these variables resulted in lowering the magnitudes of both African community dummy estimates.

The interpretation of most of the other results is straightforward. Higher levels of trust might create disappointment that could lead to a relative overshooting of punishment behavior (even when we control for the deviations from one's own contributions). Neither is it very surprising that social integration does not influence punishment behavior. In contrast to our expectations, however, variables related to community crime or violence does not influence the extent to which subjects enforce norms, either. Notably, the household violence variable exerts a significantly positive influence on sanctioning behavior. Participants who reported that they were exposed to swearing when they were young tended to punish more harshly.

There is no unambiguous explanation for the negative impact of the household reading index, but it could be related to a component of the socio-psychological literature indicating a relationship between juvenile delinquency and reading ability in adolescents (Keilitz and Dunivant 1986; Cornwall and Bawden 1992; Williams and McGee 1996). An alternative explanation is that children from highly-educated households are more able to understand that punishment in a one-shot setting is non-strategic and, therefore, irrational from the standard viewpoint in economics. ${ }^{17}$

We also conducted similar robustness checks for norm enforcement behavior as for the determinants of cooperation. Our results and conclusions remain largely unchanged.

\subsection{Reaction to the introduction of a norm enforcement device}

Recall from the non-parametric analysis that only the white community increased contribution levels significantly in Part II compared to Part I. In order to test the robustness of this result when using parametric analyses we run a series of OLS regressions with the change in contribution on the subject level between the two parts (i.e., $c_{2 i}-c_{1 i}$ ) as the dependent variable. Although a lot of subjects increase their contributions when a punishment

17 However, as mentioned before, all participants had had to answer a set of control questions regarding the game before it started. We, thus, ensured that everybody had a good understanding of the game. 
option is introduced (with the strongest effect for the participants from the white community), the community dummies and other controls are not significant in these regressions. This is mainly due to the fact that a majority of subjects naturally do not change their contribution behavior (most of them because they contributed a lot already in Part I), and the remaining number of observations is not large enough to elicit significant differences between the four communities in our one-shot setting. ${ }^{18}$ Note that it would be very surprising if subjects had changed their contributions significantly, because there was no possibility to learn.

We can also calculate ex post, what change would have been optimal behaviorally. This requires making certain assumptions regarding the contribution behavior of other group members and taking the punishment structure contingent on contribution level as given for each of the communities. Form such an exercise it is far from clear that an increase above the average contribution levels, indeed, would have been optimal for our subjects. Ex-post money-maximizing levels of contributions for the four communities lie all between zero and 15 for the given punishment structure in the communities.

\section{Discussion and Conclusion}

Our study brings new insights to the difference of cooperative norms, their nature and their determinants. We conducted one-shot public goods games with and without punishment at four schools in Cape Town, South Africa, each representing communities from different socio-demographic and population groups. By studying behavior within one geographical setting, we were able to keep differences in formal institutions, legislature, and political system constant-factors that often affect cross-cultural studies conducted in different countries. Our experiments gave us a unique data set that adds insights to the existing economics literature on cooperation and norm enforcement.

Even though the chosen schools were all within a distance of 15 kilometers from each other, we found significant differences in behavior in terms of cooperation and punishment. Hence, social norms and norms regarding the enforcement of social outcomes may be very different in different groups even in the same country. "Cultural” learning seems to establish group norms that are different within tiny geographical distances. The four groups in this study come from the white, colored, and African populations. Two locations were sampled in the African community, distinguishing areas with permanent and informal housing, in order

\footnotetext{
${ }^{18}$ Detailed results are available on request.
} 
to be able to assess possible differences from the effects of housing development and associated socio-economic conditions on behavior.

We found that participants from both African communities contributed and punished significantly more than did the white and colored participants, with those from the African informal housing areas contributing and punishing most. A large fraction of the differences in cooperative behavior vanishes once we control for socio-demographics, trust, and social background variables. Especially, gender and trust seem to play an important role in mediating the effects of the community dummies in our subject pool when it comes to cooperation.

Regarding norm enforcement behavior, i.e., punishment, the stronger inclination to punish among the members of the two African communities does not become insignificant when we control for our set of background variables, even though the size of the effect decreases a bit. A higher level of trust increases punishment, as did a higher level of selfreported psychological violence or swearing in one's youth.

There are several potential reasons that could be able to explain the observed differences between the communities. One of them has been invoked quite often in political discussions in South Africa: the concept of Ubuntu, a special term in Xhosa for expressing empathy and solidarity with one's group (i.e. for the whole being greater than the parts). Its prevalence among the African communities could be one explanation for (slightly) higher levels of cooperation and (strongly) higher levels of norm enforcement. However, a traditional group-oriented norm, such as Ubuntu, cannot explain the whole story, given that we observed significant differences in behavior also between the two African communities.

There is another general lesson to be drawn from our results. At least with nonstandard subject pools, it seems important to control for socio-demographic variables (and perhaps even background variables) in order to avoid drawing premature conclusions. If we had just relied on the school dummies, we would have interpreted our results only in terms of "cultural" differences between communities instead of being more cautious and concluding that they could also partly be driven by socio-demographic variables or social background variables, especially when it comes to cooperation. It seems to be the case that the average variance of behavior within a given culture, community, or group is at least as relevant as the variance across cultures, communities, or groups, and this insight should probably be taken into account to a greater extent, when interpreting the results from experiments that compare the behavior of different groups of participants.

We are convinced that a better knowledge of the determinants of cooperative behavior and norm enforcement, be they socio-demographic, group- or experience-related, will benefit 
economic understanding and modeling. In the future, researchers may be able to use larger subject pools of non-university students to address these questions. However, even though larger subject pools would allow detecting a greater number of significant links between background and behavior, it is not clear whether they would reveal a greater number of economically relevant links. Our subject pool seems large enough to be able to capture the most important factors that impact cooperation and punishment. Whether the differences between groups that we found in South African students are indicative for cooperative and norm enforcement behavior of similar groups in other countries or other population groups, however, is an empirical question that has to be addressed in the future.

In addition to social background variables, we think that the relationship between trust as a building block for social capital, on the one hand, and cooperative and norm enforcement behavior on the other hand, has to be studied in more detail. The two seem to be intimately related, and they also seem to interact with (fulfilled or disappointed) expectations, but we are not aware of economic studies that go beyond establishing the empirical correlation between trust and cooperation. Our study adds an additional link, namely between trust and punishment behavior, and it suggests that understanding these mutual influences could be beneficial when it comes to understand the economics of cooperation more comprehensively. 


\section{References}

Anderson, C.M., and L. Putterman. 2006. "Do Non-strategic Sanctions Obey the Law of Demand? The Demand for Punishment in the Voluntary Contribution Mechanism,” Games and Economic Behavior 54: 1-24.

Anderson, L.R., J.M. Mellor, and J. Milyo. 2004. "Social Capital and Contributions in a Public-Goods Experiment,” American Economic Review, Papers and Proceedings 94: 373-76.

Andreoni, J., W. Harbaugh, and L. Vesterlund. 2003. "The Carrot or the Stick: Rewards, Punishments, and Cooperation,” American Economic Review 93: 893-902.

Brandts, J., T. Saijo, and A.J.H.C. Schram. 2004. "A Four Country Comparison of Spite and Cooperation in Public Goods Games,” Public Choice 119: 381-424.

Burlando, R.M., and J.D. Hey. 1997. “Do Anglo-Saxons Free Ride more?” Journal of Public Economics 64: 41-60.

Carpenter, J. 2007. “The Demand for Punishment,” Journal of Economic Behavior and Organization 62: 522-42.

Carpenter, J., A. Daniere, and L. Takahashi. 2004. "Cooperation, Trust, and Social Capital in Southeast Asian Urban Slums,” Journal of Economic Behavior and Organization 55: 533-52.

Cason, T., T. Saijo, and T. Yamato. 2002. "Voluntary Participation and Spite in Public Good Provision Experiments: An International Comparison,” Experimental Economics 5: 133-53.

Cornwall, A., and H. Bawden. 1992. "Reading Disability, and Aggression: A Critical Review,” Journal of Learning Disability 25: 281-88.

Croson, R. 2007. "Theories of commitment, altruism and reciprocity: evidence from linear public goods games,” Economic Inquiry 45: 199-216.

Croson, R., and U. Gneezy. 2009. “Gender Differences in Preferences,” Journal of Economic Literature 47: 448-74.

Falk, A., E. Fehr, and U. Fischbacher. 2005. "Driving Forces behind Informal Sanctions," Econometrica 73: 2017-30.

Fehr, E., and S. Gächter. 2000. “Cooperation and Punishment in Public Goods Experiments,” American Economic Review 90: 980-94. 
Fischbacher, U., and S. Gächter. 2009. "Heterogeneous Social Preferences and the Dynamics of Free Riding in Public Goods.” American Economic Review, forthcoming.

Fischbacher, U., S. Gächter, and E. Fehr. 2001. "Are People Conditionally Cooperative? Evidence from a Public Goods Experiment,” Economic Letters 71: 397-404.

Gürerk, Ö., B. Irlenbusch, and B. Rockenbach. 2006. "The Competitive Advantage of Sanctioning Institutions,” Science 312: 108-111.

Gächter, S., B. Herrmann, and C. Thöni. 2004. "Trust, Voluntary Cooperation, and SocioEconomic Background: Survey and Experimental Evidence,” Journal of Economic Behavior and Organization 55: 505-531.

Gächter, S., and B. Herrmann. 2007. "The Limits of Self-Governance in the Presence of Spite: Experimental Evidence from Urban and Rural Russia.” CeDEx Discussion Paper. Nottingham, UK: Center for Decision Research and Experimental Economics (CeDEx), University of Nottingham.

- 2009. "Reciprocity, Culture, and Human Cooperation: Previous Insights and a New Cross-Cultural Experiment," Philosophical Transactions of the Royal Society B: Biological Sciences 364: 791-806.

Harbaugh, W.T., and K. Krause. 2000. "Children's Contributions in Public Good Experiments: The Development of Altruistic and Free-Riding Behaviors,” Economic Inquiry 38: 95-109.

Harrison, G., and J. List. 2004. “Field Experiments”, Journal of Economic Literature 42: 1009-1055.

Herrmann, B., C. Thöni, and S. Gächter. 2008. “Anti-Social Punishment across Societies,” Science 319: 1362-67.

Henrich, J., R. Boyd, S. Bowles, H. Gintis, E. Fehr, C. Camerer, R. McElreath, M. Gurven, K. Hill, A. Barr, J. Ensminger, D. Tracer, F. Marlow, J. Patton, M. Alvard, F. GilWhite, and N. Henrich. 2005. “'Economic Man’ in Cross-Cultural Perspective: Ethnography and Experiments from 15 Small-Scale Societies,” Behavioral and Brain Sciences 28: 795-855.

Keilitz, I., and N. Dunivant. 1986. "The Relationship between Learning Disability and Juvenile Delinquency: Current State of Knowledge,” Remedial and Special Education 7:18-26.

Kocher, M., T. Cherry, S. Kroll, R. Netzer, and M. Sutter. 2008. “Conditional Cooperation on Three Continents,” Economics Letters 101: 175-78. 
Lam, D., J. Seekings, and M. Sparks. 2006. “The Cape Area Panel Study (CAPS): Overview and Technical Documentation for Waves 1-2-3.” Cape Town, South Africa: CAPS, University of Cape Town. http://caps.psc.isr.umich.edu/documentation/

Ledyard, J.O. 1995. “Public Goods: A Survey of Experimental Research.” In The Handbook of Experimental Economics, edited by J. Kagel and A. Roth. Princeton: Princeton University Press: 111-94.

Masclet, D., C. Noussair, S. Tucker, and M.-C. Villeval. 2003. "Monetary and Non-monetary Punishment in the Voluntary Contributions Mechanism,” American Economic Review 93: 366-80.

Ockenfels, A., and J. Weimann. 1999. "Types and Patterns: An Experimental East-WestGerman Comparison of Cooperation and Solidarity,” Journal of Public Economics 71: $275-87$.

Ostrom, E., J. Walker, and R. Gardner. 1992. "Covenants with and without a Sword: SelfGovernance is Possible,” American Political Science Review 86: 404-417.

Sefton, M., R. Shupp, and J. Walker. 2007. "The Effect of Reward and Sanctions in the Provision of Public Goods,” Economic Inquiry 45: 671-90.

South Africa Department of Labor. 2006. Basic Conditions of Employment Amendment Act, 2002. (Amends the Basic Conditions of Employment Act, 1997). http://www.labour.gov.za/.

Stats SA (Statistics South Africa). 2003. Census 2001. Pretoria: Statistics South Africa.

Sutter, M., S. Haigner, and M.G. Kocher. 2006. "Choosing the Carrot or the Stick? Endogenous Institutional Choice in Social Dilemma Situations.” DP 5497. London: Center for Economic Policy Research (CEPR).

Williams, S., and R. McGee. 1994. “Reading Attainment and Juvenile Delinquency,” Journal of Child Psychology and Psychiatry 35: 441-59.

Yamagishi, T. 1986. “The Provision of a Sanctioning System as a Public Good,” Journal of Personality and Social Psychology 51: 110-16.

Zelmer, J. 2003. "Linear Public Goods Experiments: A Meta-Analysis,” Experimental Economics 6: 299-310. 


\section{Appendix: Variables and Non-parametric Significance Tests}

Table A1. Descriptive Statistics of Explanatory Variables.

\begin{tabular}{|c|c|c|c|c|c|c|c|c|c|c|c|c|c|c|c|}
\hline \multirow{2}{*}{ Variable } & \multicolumn{3}{|l|}{ White } & \multicolumn{3}{|c|}{ Colored } & \multicolumn{3}{|c|}{ African permanent } & \multicolumn{3}{|c|}{ African informal } & \multicolumn{3}{|l|}{ Pooled } \\
\hline & Mean & Min. & Max. & Mean & Min. & Max. & Mean & Min. & Max. & Mean & Min. & Max. & Mean & Min. & Max. \\
\hline Female & $55 \%$ & & & $80.9 \%$ & & & $67.8 \%$ & & & $77.9 \%$ & & & $70.8 \%$ & & \\
\hline Age & 16.3 & 15 & 18 & 17.00 & 15 & 19 & 18.12 & 16 & 23 & 17.33 & 15 & 21 & 17.18 & 15 & 23 \\
\hline Trust: in schoolmates & 4.35 & 4.1 & 4.59 & 3.95 & 3.71 & 4.2 & 3.36 & 3.0 & 3.71 & 2.93 & 2.56 & 3.3 & 3.67 & 3.5 & 3.82 \\
\hline $\begin{array}{l}\text { Social integration: } \\
\text { Participate in school } \\
\text { organizations }\end{array}$ & 0.53 & 0.44 & 0.62 & 0.38 & 0.29 & 0.47 & 0.50 & 0.40 & 0.59 & 0.51 & 0.42 & 0.6 & 0.48 & 0.43 & 0.52 \\
\hline $\begin{array}{l}\text { Community crime: } \\
\text { Housebreaking }\end{array}$ & 1.78 & 1.33 & 2.23 & 1.61 & 1.21 & 2.03 & 2.96 & 2.35 & 3.57 & 2.74 & 2.12 & 3.36 & 2.24 & 1.98 & 2.5 \\
\hline $\begin{array}{l}\text { Household violence: } \\
\text { Swearing }\end{array}$ & 2.48 & 2.27 & 2.69 & 2.47 & 2.29 & 2.65 & 2.72 & 2.49 & 2.95 & 2.62 & 2.35 & 2.8 & 2.57 & 2.46 & 2.68 \\
\hline Household reading index & 0.9 & 0.75 & 1.04 & 0.24 & 0.07 & 0.40 & -0.7 & -0.81 & -0.59 & -0.52 & -0.64 & -0.4 & 0 & -0.89 & 0.89 \\
\hline
\end{tabular}



Table A2. P-values from Pair-Wise Tests of Public Goods Contributions in Part I.

\begin{tabular}{|c|c|c|c|c|c|}
\hline & & White & Colored & $\begin{array}{l}\text { African } \\
\text { permanent }\end{array}$ & $\begin{array}{l}\text { African } \\
\text { informal }\end{array}$ \\
\hline \multirow{3}{*}{ White } & Contribution & $\mathrm{x}$ & $\mathrm{x}$ & $\mathrm{x}$ & $\mathrm{x}$ \\
\hline & Proportion & $\mathrm{x}$ & $\mathrm{x}$ & $\mathrm{x}$ & $\mathrm{x}$ \\
\hline & $\begin{array}{l}\text { Conditional } \\
\text { contribution }\end{array}$ & $\mathrm{x}$ & $\mathrm{x}$ & $\mathrm{x}$ & $\mathrm{x}$ \\
\hline \multirow{3}{*}{ Colored } & Contribution & 0.048 & $\mathrm{x}$ & $\mathrm{x}$ & $\mathrm{x}$ \\
\hline & Proportion & 0.062 & $\mathrm{x}$ & $\mathrm{x}$ & $\mathrm{x}$ \\
\hline & $\begin{array}{l}\text { Conditional } \\
\text { contribution }\end{array}$ & 0.363 & $\mathrm{x}$ & $\mathrm{x}$ & $\mathrm{x}$ \\
\hline \multirow{3}{*}{$\begin{array}{l}\text { African } \\
\text { permanent }\end{array}$} & Contribution & 0.029 & 0.526 & $\mathrm{x}$ & $\mathrm{x}$ \\
\hline & Proportion & 0.022 & 0.563 & $\mathrm{x}$ & $\mathrm{x}$ \\
\hline & $\begin{array}{l}\text { Conditional } \\
\text { contribution }\end{array}$ & 0.432 & 0.725 & $\mathrm{x}$ & $\mathrm{x}$ \\
\hline \multirow{3}{*}{ African informal } & Contribution & 0.000 & 0.019 & 0.123 & $\mathrm{x}$ \\
\hline & Proportion & 0.007 & 0.321 & 0.693 & $\mathrm{x}$ \\
\hline & $\begin{array}{l}\text { Conditional } \\
\text { contribution }\end{array}$ & 0.017 & 0.029 & 0.111 & $\mathrm{x}$ \\
\hline
\end{tabular}

Note: We applied Wilcoxon-Mann-Whitney tests to test the null hypothesis that the contributions (and conditional contributions) in two tested, independent communities are drawn from the same population. The null hypothesis of same proportion is tested by using a chi-square tests. 
Table A3. P-values from Pair-Wise Tests from Public Goods Contributions in Part II.

\begin{tabular}{|c|c|c|c|c|c|}
\hline & & White & Colored & $\begin{array}{l}\text { African } \\
\text { permanent }\end{array}$ & $\begin{array}{l}\text { African } \\
\text { informal }\end{array}$ \\
\hline \multirow{3}{*}{ White } & Contribution & $\mathrm{x}$ & $\mathrm{x}$ & $\mathrm{x}$ & $\mathrm{x}$ \\
\hline & Proportion & $\mathrm{x}$ & $\mathrm{x}$ & $\mathrm{x}$ & $\mathrm{x}$ \\
\hline & $\begin{array}{l}\text { Conditional } \\
\text { contribution }\end{array}$ & $\mathrm{x}$ & $\mathrm{x}$ & $\mathrm{x}$ & $\mathrm{x}$ \\
\hline \multirow{3}{*}{ Colored } & Contribution & 0.612 & $\mathrm{x}$ & $\mathrm{x}$ & $\mathrm{x}$ \\
\hline & Proportion & 0.436 & $\mathrm{x}$ & $\mathrm{x}$ & $\mathrm{x}$ \\
\hline & $\begin{array}{l}\text { Conditional } \\
\text { contribution }\end{array}$ & 0.667 & $\mathrm{x}$ & $\mathrm{x}$ & $\mathrm{x}$ \\
\hline \multirow{3}{*}{$\begin{array}{l}\text { African } \\
\text { permanent }\end{array}$} & Contribution & 0.057 & 0.153 & $\mathrm{x}$ & $\mathrm{x}$ \\
\hline & Proportion & 0.004 & 0.024 & $\mathrm{x}$ & $\mathrm{x}$ \\
\hline & $\begin{array}{l}\text { Conditional } \\
\text { contribution }\end{array}$ & 0.911 & 0.637 & $\mathrm{x}$ & $\mathrm{x}$ \\
\hline \multirow{3}{*}{ African informal } & Contribution & 0.010 & 0.024 & 0.415 & $\mathrm{x}$ \\
\hline & Proportion & 0.040 & 0.163 & 0.338 & $\mathrm{x}$ \\
\hline & $\begin{array}{l}\text { Conditional } \\
\text { contribution }\end{array}$ & 0.154 & 0.171 & 0.105 & $\mathrm{x}$ \\
\hline
\end{tabular}

Note: We applied Wilcoxon-Mann-Whitney tests to test the null hypothesis that the contributions (and conditional contributions) in two tested independent communities are drawn from the same population. The null hypothesis of same proportion is tested by using a chi-square tests. 
Table A4. P-values from Tests between Part I and Part II.

\begin{tabular}{llll} 
& Contribution & Proportion & Conditional contribution \\
\hline White & 0.063 & 0.225 & 0.162 \\
Colored & 0.739 & 0.527 & 0.462 \\
African permanent & 0.245 & 0.046 & 0.718 \\
African informal & 0.909 & 1.000 & 0.876 \\
\hline $\begin{array}{l}\text { Overall } \\
\text { Note: We applied Wilcoxon matched-pairs signed-ranks tests to test the null hypothesis that the contributions (and } \\
\text { conditional contributions) in the two parts are drawn from the same population. The null hypothesis of same } \\
\text { proportion is tested by using McNemar tests. }\end{array}$ & 0.262 \\
\hline
\end{tabular}

Table A5. P-values from Pair-Wise Tests from Punishment in Part II.

\begin{tabular}{|c|c|c|c|c|c|}
\hline & & White & Colored & $\begin{array}{l}\text { African } \\
\text { permanent }\end{array}$ & $\begin{array}{l}\text { African } \\
\text { informal }\end{array}$ \\
\hline \multirow{3}{*}{ White } & Punishment & $\mathrm{x}$ & $\mathrm{x}$ & $\mathrm{x}$ & $\mathrm{x}$ \\
\hline & Proportion & $\mathrm{x}$ & $\mathrm{x}$ & $\mathrm{x}$ & $\mathrm{x}$ \\
\hline & $\begin{array}{l}\text { Conditional } \\
\text { punishment }\end{array}$ & $\mathrm{x}$ & $\mathrm{x}$ & $\mathrm{x}$ & $\mathrm{x}$ \\
\hline \multirow{3}{*}{ Colored } & Punishment & 0.894 & $\mathrm{x}$ & $\mathrm{x}$ & $\mathrm{x}$ \\
\hline & Proportion & 0.892 & $\mathrm{x}$ & $\mathrm{x}$ & $\mathrm{x}$ \\
\hline & $\begin{array}{l}\text { Conditional } \\
\text { punishment }\end{array}$ & 0.082 & $\mathrm{x}$ & $\mathrm{x}$ & $\mathrm{x}$ \\
\hline \multirow{3}{*}{$\begin{array}{l}\text { African } \\
\text { permanent }\end{array}$} & Punishment & 0.000 & 0.000 & $\mathrm{x}$ & $\mathrm{x}$ \\
\hline & Proportion & 0.000 & 0.000 & $\mathrm{x}$ & $\mathrm{x}$ \\
\hline & $\begin{array}{l}\text { Conditional } \\
\text { punishment }\end{array}$ & 0.000 & 0.024 & $\mathrm{x}$ & $\mathrm{x}$ \\
\hline \multirow{3}{*}{ African informal } & Punishment & 0.000 & 0.000 & 0.159 & $\mathrm{x}$ \\
\hline & Proportion & 0.000 & 0.000 & 0.250 & $\mathrm{x}$ \\
\hline & $\begin{array}{l}\text { Conditional } \\
\text { punishment }\end{array}$ & 0.000 & 0.002 & 0.387 & $\mathrm{x}$ \\
\hline
\end{tabular}

